Western University

Scholarship@Western

Centre for Human Capital and Productivity. CHCP

Working Papers

2005

2005-4 What Can Be Learned about Peer Effects Using College Roommates? Evidence from New Survey Data and Students from Disadvantaged Backgrounds

Todd R. Stinebrickner

Ralph Stinebrickner

Follow this and additional works at: https://ir.lib.uwo.ca/economicscibc

Part of the Economics Commons

Citation of this paper:

Stinebrickner, Todd R., Ralph Stinebrickner. "What Can Be Learned about Peer Effects Using College Roommates? Evidence from New Survey Data and Students from Disadvantaged Backgrounds." CIBC Centre for Human Capital and Productivity. CIBC Working Papers, 2005-4. London, ON: Department of Economics, University of Western Ontario (2005). 


\section{What Can Be Learned About Peer Effects Using College Roommates? Evidence From New Survey Data And Students From Disadvantaged Backgrounds}

\section{by}

Todd R. Stinebrickner and Ralph Stinebrickner

\section{CIBC Working Paper Series}

Department of Economics Social Science Centre The University of Western Ontario

London, Ontario, N6A 5C2 Canada

This working paper is available as a downloadable pdf file on our website http://economics.uwo.ca/centres/cibc/ 
What can be learned about peer effects using college roommates?

Evidence from new survey data and students from disadvantaged backgrounds

Todd R. Stinebrickner and Ralph Stinebrickner

Please direct correspondence to

Todd Stinebrickner

Dept. of Economics

Social Science Centre

The University of Western Ontario

London, Ontario Canada

$\mathrm{N} 6 \mathrm{~A} 5 \mathrm{C} 2$

trstineb@julian.uwo.ca

519 661-2111 ext 85293

fax: 519 661-3666

\begin{abstract}
:
Previous papers which examine the importance of peer effects using exogenous variation in college roommates have found only very limited evidence that a student's first year grade performance is influenced by the observable academic characteristics of his/her roommate. One possible explanation for this finding is that peer effects do not play a particularly important role in the higher education setting. However, another very plausible explanation for this finding is that peer effects are important in higher education but that these previous empirical efforts have simply not been "looking in the right place" to find the evidence of peer effects in this setting. Thus, while these papers have received considerable attention due to the general difficulty of finding credible exogenous variation in peer quality, they have difficulty answering the most fundamental question related to peer effects in this higher education - whether peer effects play an important role or not. This paper provides depth to the peer effects literature using unique new survey and administrative data.
\end{abstract}

keywords: peer effects, education, educational attainment, higher education, poverty

JEL codes: I2 - Education, J - Labor and Demographic Economics 
Peer effects have the potential to play important roles in determining the impact of many current and potential education policies. Unfortunately, determining the nature and importance of peer effects in either lower or higher education is a difficult task. The empirical difficulty stems from the reality that a given student's classmates and friends are determined by a complex set of decisions made by the student, the student's parents, and/or school administrators and teachers. This non-randomness creates problems of inference because it implies that unobservable determinants of a particular student's academic outcomes may tend to be systematically related to the observable and unobservable characteristics of his/her friends or classmates.

This empirical difficulty was emphasized recently by Sacerdote (2001) and Zimmerman (2003) who reviewed past literature on peer effects and proposed a way to obtain information about the importance of peer effects. ${ }^{1}$ Specifically, the authors suggested that a student's first year college roommate has a potentially important influence on the student's first year college experience and outcomes. Thus, if the housing assignment process is such that these peers are randomly assigned or are randomly assigned conditional on information that is known to the researcher, the relationship between the college outcomes of students and the characteristics of their roommates represents a causal impact of peers that is not clouded by the problematic bias that may be present when students' peers are endogenously determined. In terms of academic outcomes, Sacerdote and Zimmerman examined the relationship between a student's first-year college grade point average and certain observable academic characteristics of his/her roommate.

These papers find only very limited evidence that a student's first year grade performance is influenced by the observable academic characteristics of his/her roommate. ${ }^{2}$ One possible explanation for

\footnotetext{
${ }^{1}$ The authors present a review of past theoretical and empirical work on peer effects. Given the thoroughness of the review, we have chosen not to repeat it here.

${ }^{2}$ Sacerdote (2001) finds no evidence that a student's first year grade point average is influenced by his/her roommate's score on an academic index created by the Dartmouth admissions office if this score is included in the specified grade regression in a linear fashion. In a different specification, having a roommate with an academic index score in the top $25 \%$ is found to increase a student's grade point average by .033 relative to having a roommate with a score in the bottom $25 \%$ and by .047 relative to having a roommate with a score in the middle $50 \%$. A test of the null hypothesis that there is no difference between having a roommate in the top $25 \%$ and having a roommate in the bottom $25 \%$ is not rejected at standard significance levels. A test of the null hypothesis that there
} 
this finding is that peer effects do not play a particularly important role in higher education. However, another very plausible explanation for this finding is that peer effects are important in higher education but that these previous empirical efforts have simply not been "looking in the right place" to find the evidence of peer effects. Thus, while these papers have received considerable attention due to the general difficulty of finding credible exogenous variation in peer quality, the reality that these papers find little evidence implies that they have difficulty providing much information about the most fundamental question related to peer effects in higher education - whether peer effects play an important role or not. ${ }^{4}$

Understanding why these previous studies find such little evidence is fundamental to the understanding of whether peer effects are important in this context. Unfortunately, this issue is not easily examined with standard survey data of the type used in the previous studies. To see this, consider three interrelated reasons that previous studies may not have been "looking in the right place" to find evidence of peer effects. First, it is not clear that previous studies have been looking at the performance of the types of students who would benefit substantially from peers. While policy interest in peer effects typically arises in contexts where some of the students of interest are of low ability or are from disadvantaged backgrounds, virtually all students at Dartmouth College and Williams College which are studied by Sacerdote (2001) and

is no difference between a roommate in the top $25 \%$ and a roommate in the middle $50 \%$ yields a t-statistic of 1.81 .

${ }^{3}$ Zimmerman (2003) finds no evidence that a student's first year grade point average is influenced by his/her roommate's total Scholastic Aptitude Test (SAT) score. He finds evidence that a student's first year grades are positively correlated with his/her roommate's verbal SAT score if the roommate's math SAT score is also included in the regression specification. However, the estimated effect of math SAT scores is negative and the paper does not provide direct evidence of whether students benefit from having roommates with higher verbal SAT scores after taking into account that, on average, these students also are likely to have higher math SAT scores.

${ }^{4}$ Because of the interpretation difficulties described above, this is a case in which there is an asymmetry between the amount that could have been learned from a "positive" finding and the amount that can be learned from the finding that there is little evidence of a relationship.

The difficulty of providing credible evidence about peer effects has been well-recognized. As some evidence of this reality, despite the fact that the papers of Sacerdote and Zimmerman have difficulty providing much information about whether peer effects play an important role or not in higher education, Hoxby (2000) writes, "Some of the most convincing estimates of peer effects come from policy or natural experiments at the college or neighborhood level. For instance, Zimmerman and Sacerdote estimate the effects of college roommates who are conditionally randomly assigned at Williams College and Dartmouth College, respectively." 
Zimmerman (2003) respectively are of very high quality. ${ }^{5}$ The reality that virtually all entering students at Dartmouth and Williams are likely to arrive at school with strong academic ability, good study habits, and strong beliefs about the importance of college may substantially mitigate the potential influence of peer effects. $^{6}$

Second, even if a student at the types of schools being studied would benefit substantially from good peers, it is not clear that a student's randomly assigned roommate represents a peer of "potential influence." From a theoretical standpoint, it is not immediately obvious what type of relationship should be expected between individuals who are randomly assigned to the same room as freshmen. On one hand, the roommates may spend a substantial amount of time together out of necessity or because the "forced" interaction between them leads to an actual friendship. On the other hand, if indeed the roommate is randomly drawn from the distribution of freshmen at the school, a student may find that there are many other students at the school who have more compatible interests and preferences than his/her roommate. If the latter is the dominant factor in friendship formation, it may not make sense to examine freshmen roommates if one is interested in looking for evidence of peer effects.

Finally, even if a student at these schools would benefit substantially from the presence of good peers and the roommate represents a peer of potential influence, it is not clear that previous studies have successfully pinpointed the observable characteristics of roommates that are most likely to be related to peer "quality" in this context. An important point that has not been discussed in these previous papers is that roommate peer effect studies, by necessity, focus on academic outcomes that take place relatively quicky after a student receives the "treatment" of being assigned a roommate. In the short run it seems likely that a

\footnotetext{
${ }^{5}$ It was very natural for the authors to study these schools because they had important knowledge about institutional details. However, Dartmouth College is the $6^{\text {th }}$ or $7^{\text {th }}$ most selective undergraduate school in the U.S. based on college entrance exam scores and high school rank. The average combined SAT score at Williams College places the average student in the top $10 \%$ of the population of test takers and the average combined SAT score of students in the lowest $15 \%$ of the Williams class would be at about the $75^{\text {th }}$ percentile in the population.

${ }^{6}$ This possibility is one of the primary motivating factors for the recent work of Foster (2003) who examines students at the University of Maryland.
} 
student's academic ability is to a large extent fixed but that a student's decisions about time-use and study habits can be influenced. This suggests that the primary avenue through which first-year college roommates can serve as good peers is by acting as positive role models and by encouraging conscientious study habits and effort. Thus, if variation in a particular observable characteristic tends to primarily capture differences in academic ability per se rather than whether a person has habits or beliefs that would make him/her a good role model, then perhaps we should not expect a strong relationship between college grades and that observable characteristic of roommates.

While the first of these three reasons for a lack of evidence of peer effects in previous studies could be examined using administrative data from a different school with more diversity, this approach would typically be of little use in understanding the importance of the second and third reasons since administrative data cannot provide direct evidence about friendship formations and issues such as time-use. The contribution of this paper is that, by taking advantage of unique new survey data that we have collected at a school with substantial student heterogeneity, we are able to think about all three of the reasons described above. The school we examine is Berea College which is located in central Kentucky where the "Bluegrass meets the foothills of the Appalachian Mountains.” The unique features of the data are introduced in Section II with additional detail provided in the subsequent sections of the paper. With respect to the first reason discussed above, a descriptive view of students indicates that students at Berea are often of the type that policy discussion has suggested might benefit the most from having good peers. In Section III, we provide information about the second reason discussed above by taking advantage of unique survey data to explore the relationship between students and their randomly assigned roommates. Roughly speaking, we find that it seems reasonable to think of randomly assigned roommates as peers of "potential influence," although there is some evidence that some of the substantial interactions between roommates occur out of necessity rather than because the roommates have become good friends. Section IV is motivated by the third reason discussed above. We begin by discussing in more detail the avenues through which it seems logical that roommates might make good peers in this particular educational context. Our discussion, taken together with an 
examination of both unique survey data about the academic interactions between randomly assigned roommates and unique survey data on student time-use, provides guidance about which observable characteristics would most plausibly be related to peer quality at this school and suggests that, at least at Berea, it would not be particularly informative to look for evidence of peer effects using the types of measures used in past work.

In Section $\mathrm{V}$ we examine whether we can find evidence of peer effects at Berea. We find evidence using the types of roommate characteristics that our simple intuition/theory and empirical work in Section IV suggest are more likely to be related to peer quality. We find differences in the importance of peer effects by sex and, using our unique survey data, are able to provide empirical evidence for why these differences exist. Section VI concludes.

\section{Berea College, Data, and the Roommate Assignment Process}

Our analysis involves both the use of administrative data from the period 1991-1996 and unique survey data from the years 2000-2001. In the next two subsections we describe how we use the data from each period and our rationale for these uses, describe the housing assignment process at Berea, and provide a descriptive view of students at Berea.

\section{II.1 Administrative data from the period 1991-1996}

In Section V, where we look for evidence of a relationship between a student's outcomes and the characteristics of his/her roommate, we use administrative data for a sample of 1295 students who entered Berea College as freshmen between 1991 and 1996. Our rationale for using these data for this purpose is that the roommate assignment process was unconditionally random during this period. Specifically, during this period incoming freshmen at Berea were not asked to complete a housing preference questionnaire and were randomly placed in available rooms without reference to preferences, backgrounds, or academic ability. ${ }^{7}$

\footnotetext{
${ }^{7}$ A housing preference questionnaire has not been used in any of the years from 1991 to the present, apparently due to a belief that such questionnaires are of limited usefulness due to misreporting of behaviors such as smoking. Approximately two weeks before the start of school (and after all members of the freshman class have
} 
Nonetheless, given the importance of the randomness in this application, we provide indirect evidence in Section $\mathrm{V}$ to support this belief that the process is indeed random.

Descriptive statistics for this sample are shown in Table 1. Berea operates under a mission of providing educational opportunities to those of "great promise but limited economic resources." The INCOME entry in Table 1 , defined as the family income of a student divided by $\$ 10,000$, indicates that students at Berea tend to be economically disadvantaged with an average family income of slightly more than $\$ 21,000$. Twenty-five percent of the students in our sample come from families with income of less than $\$ 11,400$. The wealthiest twenty-five percent of the students in our sample come from families with income of greater than $\$ 30,700$ and less than approximately $\$ 70,000$.

The majority of students at Berea take the American College Test (ACT), and, when necessary, we convert Scholastic Aptitude Test (SAT) scores to ACT equivalents. In the remainder of the paper we use combined math and verbal ACT scores (math ACT + verbal ACT), but we have found essentially no difference in the results when ACT math and verbal scores are included separately in the empirical work. The 10th percentile, median, and $90^{\text {th }}$ percentile for verbal ACT scores at Berea are 17, 22, and 28 respectively which correspond roughly to the $31 \mathrm{st}, 65$ th, and 92 nd percentiles of all ACT test takers. The 10 th percentile, median, and $90^{\text {th }}$ percentile for math ACT scores at Berea are 16, 22, and 26 respectively which correspond roughly to the 22nd, 66st, and 85 th percentiles of all ACT test takers. Table 1 also indicates a large amount of variation in high school grade point averages (HSGPA). We note that high school grades are missing for approximately $25 \%$ of our sample.

To be consistent with other work we concentrate primarily on grade outcomes, but, in addition, also mention results for a retention outcome. The grade outcome that we focus on is a person's first semester

been determined) pairs of roommates were drawn from the pool of all freshmen using a procedure which ensures randomness. In some subset of years since 1991, the process took advantage of a random assignment software that exists on the campus computer system. In other years, pairs of names were drawn manually. Freshmen are allowed to change rooms only in very rare cases where "serious, extenuating" circumstances exist. In all cases, our data contain a student's initially assigned roommate. 
grade point average $(\mathrm{G})$. The retention outcome we examine is whether the student stays in school at least until the beginning of his/her second year. Table 1 shows a large degree of variation in these outcomes. The average first semester grade point average for all students is 2.47 with a standard deviation of $.874 .^{8}$ Only .68 of all students return to Berea for their second year.

Thus, the descriptive view of students at Berea suggests that, in terms of both academic/family background and college outcomes, students at Berea tend to be much different than those used in the previous work of Sacerdote and Zimmerman and are much more likely to be of the type that policy discussion has suggested might benefit the most from having good peers.

\section{II.2 Survey Data from the Berea Panel Study for 2001-2002}

In Section III, where we examine the interactions between students and their randomly assigned roommates, and in Section IV, where we look for theoretical and empirical guidance about the type of characteristics that might be related to peer quality, we use data for students who entered Berea in the fall semesters of 2000 and 2001. Our rationale for this is that unique survey data is available for these students from the Berea Panel Study (BPS).

Todd Stinebrickner and Ralph Stinebrickner (hereafter referred to as S\&S) began the Berea Panel Study (BPS) with the explicit objective of collecting the type of detailed information that is necessary to provide a comprehensive view of the decision-making process of college students. Two cohorts were chosen with baseline surveys being administered to the first BPS cohort (the 2000 cohort) immediately before it began its freshman year in the fall of 2000 and baseline surveys being administered to the second BPS cohort (the 2001 cohort) immediately before it began its freshman year in the fall of 2001. In addition to collecting detailed background information about students and their families, the baseline surveys were designed to take advantage of recent advances in survey methodology in order to collect information about students'

\footnotetext{
${ }^{8}$ The mean (standard deviation) of first year GPA at Dartmouth is $3.20(.43)$. The mean (standard deviation) of first semester GPA at Williams is $3.10(.510)$.
} 
preferences and expectations towards uncertain future events and outcomes (e.g., academic performance, labor market outcomes, non-pecuniary benefits of school, marriage and children) that could influence decisions. Substantial follow-up surveys that are administered at the beginning and end of each subsequent semester have been designed to document the experiences of students and how various factors that might influence decisions change over time.

Of direct relevance to our analysis of Section III, which examines whether a roommate represents a peer of "potential influence," the follow-up surveys elicit information about a student's overall interactions and academic interactions with his/her roommate and his/her other friends. Of direct relevance to our analysis in Section IV, which examines what characteristics might be expected to be related to peer quality, a sequence of shorter surveys that are administered at multiple times each year have been designed to provide information about how students are using their time.

It is worth noting that, while it would be desirable to also use the data from the BPS sample period to look for evidence of peer effects in Section V, doing so is not feasible for reasons related to sample size. While roommates were unconditionally randomly assigned during the 1991-1996 period, an institutional change that took place after that period implies that not all roommates have been randomly assigned after that period. In particular, the college introduced a freshman orientation session that is held in the summer before college entrance and also allowed students the option of requesting roommates for their freshmen year. Approximately one-third of entering students now request a roommate. For freshmen who enter Berea during the 2000 and 2001 academic years we are able to identify which students did not request roommates using a question in our BPS survey. We use these students, who were randomly assigned a roommate, in our empirical work in Section IV. However, while this subset is large enough for our purposes of Section IV, it is too small for the purposes of Section $V$ where we look for evidence of peer effects. As a result, we use the data from the earlier period for that analysis. 


\section{Are roommates peers of “potential influence?”}

As discussed in the introduction, uncertainty about the relevance of the three reasons that previous studies may not have been looking in the "right place" for evidence of peer effects makes it difficult to interpret the lack of strong evidence that exists in these previous studies. In this section we examine the second of the three reasons - that students may not have substantial relationships with their first year roommates. As discussed in the introduction, this possibility is not ruled out by theory and virtually no empirical evidence currently exists about this issue.

To examine whether roommates are peers of "potential influence" we turn to data from the Berea Panel Study. For reasons related to the specifics of the survey instruments that were used, we focus on the second (2001) BPS cohort. For this cohort 375 out of 420 (.89) eligible students completed the baseline BPS survey which was a necessary condition for continued involvement in the survey. Of these 375 participants, 320 students (.85) answered a question in November (Question O in the Appendix) which elicits direct evidence about a student's interactions with his/her roommate and other friends. Ten of these students did not have roommates. Of the remaining 310 students, 204 did not request a roommate and were randomly assigned a roommate by the school.

The information collected in the second column of Question $\mathrm{O}$ in the Appendix provides evidence that students do have substantial interactions with their first year roommates. For example, on average, a student spends 21.66 hours per week with his/her roommate and 21.28 hours per week with the nonroommate that he/she spends the most time with. Forty-seven percent of students spend more time with their roommate than any other friend. At the same time, the data also suggest that some of the time spent with roommates is out of necessity. While seventy-two percent of students spend more time with their roommate than at least one of their three best (non-roommate) friends, only thirty-seven percent of students list their roommate as one of their best four friends. Thus, while the evidence suggests that it is reasonable to think of a roommate as a peer of "potential influence," as discussed in detail in the next section, it also highlights the importance of thinking carefully about the avenues through which peer effects might be expected to arise. 


\section{What observable characteristics might be related to peer quality in this context?}

A second possible reason that previous studies may not have been looking in the right place for evidence of peer effect is that these studies may not have pinpointed observable characteristics that are most plausibly related to peer quality at the particular schools being studied. In this section, we discuss the avenues through which peers effects are likely to operate in this particular context, and, given this discussion, provide some empirical evidence that is relevant for understanding what observable characteristics might be expected to be related to peer quality at this school.

There are two primary avenues through which peer effects might operate in educational contexts. First, good peers could have the effect of increasing the amount of academic material that a student can comprehend at a given effort level. Defining academic "ability" to capture both a student's innate raw intelligence and also his academic preparation at a particular point in school, this avenue could be relevant if, for example, interacting with high ability peers about the topics being covered in courses helps a low ability student understand course material more efficiently. ${ }^{9}$ Second, good peers could have the effect of changing a student's decisions about how much effort to put into his classes or could have the effect of changing a student's decisions about how much (or what type) of education to obtain conditional on a particular academic performance.

In understanding the plausibility of the first avenue in this particular educational context, it seems especially important to recognize that the freshmen outcomes in the roommate literature occur relatively quickly after a student receives the "treatment" of being assigned a roommate, and, as a result, are essentially short-run in nature. ${ }^{10}$ While the capacity of the high ability student to comprehend new material or

\footnotetext{
${ }^{9}$ The students could be helped directly with their coursework by other students or could benefit from hearing insight of other students in classroom discussion. In certain educational contexts, this avenue could also be of importance if the existence of certain types of peers influences the amount of attention that a student receives from a teacher or if the parents of particular types of students influence the quality of the school through financial or non-financial means.

${ }^{10}$ The necessity of examining first year outcomes occurs because roommates are not randomly assigned after this point.
} 
solve/analyze academic problems/questions could perhaps eventually be transmitted to some extent to the low ability student, the reality that academic ability (as defined above) has been determined in this context both by raw intelligence and by eighteen years of formal and informal schooling that takes place before a student arrives at college seems to suggest that these types of ability skills will be largely fixed in the short run.

At the very least, this avenue would only seem to be relevant if a student spends a very substantial amount of time interacting with his/her roommate on academic matters. In practice, it seems far from certain that we should expect this to be the case. Even if a high ability roommate is generally open to helping his/her low ability roommate understand the specifics of his coursework, in practice it may be quite costly for him to do so given that it is likely that the two students will not be taking the same courses. The evidence in the previous section that students spend substantial amounts of time with their roommates but often do not view their roommates as one of their four best friends raises some doubt about whether students would be willing to pay this cost to help a roommate in this fashion. In addition, the BPS allows us to provide direct evidence about the importance of this issue using the information from column 3 of question $\mathrm{O}$ in the Appendix. We find that the median student spends only approximately 20 minutes a day "studying/talking about classes" with his/her roommate. Given this relatively small number and the reality that some of these reported minutes almost certainly involve time spent studying separately in the same dorm room without actually interacting on academic matters, the discussion and evidence suggests that this first avenue is not likely to be particularly important in this particular educational context.

However, in contrast, it seems quite plausible that the second avenue might be important. S\&S (2003b) and S\&S (2004) suggest that time-use in general and study-effort more specifically play very important roles in determining grade outcomes. Further, it seems likely that at very little cost to himself/herself, a person who has conscientious study habits or strong beliefs about the importance of educational attainment could serve as a positive role model. Thus, if the presence of this type of role model influences a roommate's decisions about time-use or views about the importance of educational attainment, this second avenue could be of importance. 
Thus, the previous discussion together with evidence that the academic interactions between roommates is rather limited suggests that, if one is interested in determining whether peer effects are important in this context, it makes sense to look for evidence in roommate characteristics that are related to what kind of a role model a roommate might make rather than roommate characteristics that measure academic ability per se. In particular, given that time-use is a characteristic of role models that is readily observable by roommates, it seems logical to think about roommate characteristics that are related to time-use.

Unfortunately, in general it is difficult to know which observable roommate characteristics are related to a person's time-use behavior. For example, as discussed in $\mathrm{S} \& \mathrm{~S}(2004)$, theory alone cannot determine whether individuals with high college entrance exam scores, which to a large extent measure ability, will study more or less than other individuals. On one hand, high ability students may receive higher non-pecuniary benefits and may retain more academic information from an additional hour of studying. On the other hand, given that high ability students may achieve the maximum grade at lower amounts of studying, an additional hour of studying may lead to higher grade and future benefits for the low ability student and the low ability student may be forced to study more just to "stay afloat." Rather similar conclusions exist for other variables. For example, while there are intuitively appealing reasons to believe that a person's study effort in college may be related to his high school grade point average, the strength of this relationship (and probably even the direction of this relationship) is uncertain from a theoretical standpoint and depends on factors such as how the school weights various factors when deciding which students to admit. ${ }^{11}$

Fortunately, unique time-use data collected as part of the BPS provide us with a unique opportunity to obtain direct evidence about the relationship between student characteristics, such as college entrance exam scores and high school grade performance, and college study effort. For reasons related to the specifics of the

\footnotetext{
${ }^{11}$ Given basic intuition and evidence of the importance of time-use in S\&S (2003b, 2004), it seems likely that time use also plays an important role in the high school grade production function. Thus, at least conditional on ability, people with higher high school grade point averages are likely to have studied more in high school. To the extent that the decision about time-use during college is based on underlying individual preference and production function parameters that also influence the high school time-use decision, one would expect a person's study effort during high school to be related to his/her study effort during college.
} 
survey instruments that were used, we focus on the first (2000) BPS cohort. For this cohort, 343 out of 426 (.81) eligible students completed the baseline BPS survey which was a necessary for continued participation in the survey.

During this cohort's freshman year, six surveys were aimed primarily at eliciting information about how students were using their time. These surveys were sent to students via campus mail with strict completion deadlines. ${ }^{12}$ With respect to time spent studying, we asked each student to think carefully about how he/she had been spending his/her time and to report the amount of time he/she had spent studying and doing homework (outside of class time) in the immediately preceding twenty-four hour period. The timing of the delivery and deadlines of the surveys implies that all time-use surveys were completed on a weekday. Thus, the answers to the time-use questions represent hours of study in a twenty-four hour weekday period.

The first six rows of Table 2 show descriptive statistics associated with the study questions for each of the six time-use surveys. On average, students study approximately 3.5 hours per day. The seventh row of Table 2 shows descriptive statistics when each person's reported hours are averaged over all of the time-use surveys that the person completed. ${ }^{13}$ The sample distribution related to the reports from the first time-use survey (row 1) are shown in the remainder of Table 2.

The standard deviations of the entries in the first six rows indicate that there is a large amount of variation in study hours across individuals within a 24-hour period. The standard deviations of the entries in the seventh row indicate that permanent differences exist across people in study habits. However, the fact that the standard deviations in row 7 are smaller than those in rows 1- 6 suggests that the stochastic process that determines 24-hour study-times also contains a non-trivial non-permanent component. This motivates our estimation of a relationship between time-use and observable characteristics that contains both permanent and

\footnotetext{
${ }^{12}$ The proportion of our first-wave respondents who answered each of these time-use surveys was $.90, .82$, $.83, .77, .75$, and .75 . The slight decline in response rates between the second and sixth surveys is caused by the fact that approximately six percent of our respondents left school before the end of the first year.

${ }^{13}$ That is, we compute the average hours for each person across all of the time-use surveys that he/she completed. The descriptive statistics are the mean and standard deviation of these averages across all people in the sample.
} 
transitory components. Specifically, we estimate three separate specifications

(1a) Study $_{i, t}=$ Constant $_{t}+\gamma_{\mathrm{ACT}} \mathrm{ACT}_{\mathrm{i}}+\mu_{\mathrm{i}}+\varepsilon_{\mathrm{i}, \mathrm{t}}$

(1b) Study $_{\mathrm{i}, \mathrm{t}}=$ Constant $_{\mathrm{t}}+\gamma_{\mathrm{HSGPA}} \mathrm{HSGPA}_{\mathrm{i}}+\mu_{\mathrm{i}}+\varepsilon_{\mathrm{i}, \mathrm{t}}$

(1c) Study $_{\mathrm{i}, \mathrm{t}}=$ Constant $_{\mathrm{t}}+\gamma_{\mathrm{ACT}} \mathrm{ACT}_{\mathrm{i}}+\gamma_{\mathrm{HSGPA}} \mathrm{HSGPA}_{\mathrm{i}}+\mu_{\mathrm{i}}+\varepsilon_{\mathrm{i}, \mathrm{t}}$.

Study ${ }_{\mathrm{i}, \mathrm{t}}$ is the study-time for person i during one particular 24-hour period t when time-use was measured. The constant is allowed to vary across the time-use periods to take into account that some time-use surveys may have been collected at busier times during the year than other time-use surveys. $\mu_{\mathrm{i}}$ is a person specific random effect that takes into account that some individuals have a "permanent" propensity to study more than others, and $\varepsilon_{\mathrm{i}, \mathrm{t}}$ represents transitory variation in study time. ${ }^{14}$

The estimates associated with specification (1a) are shown in the first column of Table 3 . The point estimate (standard error) of $\gamma_{\mathrm{ACT}}$ is -.038 (.026) which implies that the hypothesis of no relationship between college entrance exam scores and study time cannot be rejected at traditional levels with high ACT students in the sample studying somewhat less than other students. The second column of Table 3 shows estimates of specification (1b) in which ACT is replaced by a person's high school grade point average, HSGPA. In this specification, the hypothesis of no relationship is rejected at all traditional significance levels with a point estimate (standard error) of .752 (.212). Further, this effect is quantitatively important. Using the descriptive statistics in Table 1, an increase in a student's HSGPA from one standard deviation below the mean to one standard deviation above the mean would increase average study-time in a day by approximately $25 \%$. Finally, the third column of Table 3 shows estimates of specification (1c) which includes both ACT and HSGPA. In this specification, the estimated effect of HSGPA increases to 1.04 and a test of the null hypothesis of no relationship between HSGPA and study time is rejected with a t-statistic of 4.661 .

Thus, the discussion and empirical results suggest that, if roommates do provide peer benefits at Berea, we may be more likely to find evidence of this in the relationship between college grades and a roommate's

\footnotetext{
${ }^{14} \mathrm{We}$ assume that the transitory component is serially uncorrelated across time. A formal test in S\&S (2004) indicates that this is a reasonable assumption.
} 
HSGPA than in the relationship between college grades and a roommate's ACT score. ${ }^{15}$ In the next section we examine whether this is the case, and we also examine the effect of an additional peer variable which our discussion suggests might be related to whether a person is a good role model - although for institutional reasons described later it does not make sense to try to verify this in this section using our time-use information from the BPS.

\section{Is there evidence of peer effects at Berea?}

Section II, which indicates that students at Berea are of the type that might benefit from having good peers, and Section III, which indicates that roommates are peers of potential influence, suggest that it is reasonable to look for evidence of peer effects at Berea by taking advantage of exogenous variation in college roommates. We do this in this section with our discussion and results in Section IV providing guidance for our empirical work.

Section IV suggested that we should perhaps not expect to find evidence that a student's outcomes are related to the ACT scores of his/her roommate but that we might find such evidence using the high school GPA of his/her roommate. Here we suggest another variable that our intuition suggests might imply that a student in our 1991-1996 sample is a good role model. Berea College is unique in that it offers a full tuition and room and board subsidies to all entering students regardless of family income. S\&S (2003a) finds that, despite direct costs of approximately zero for all students, family income played an important role in the 19911996 period in determining both the college grades and retention of students at Berea even after controlling for observable characteristics including college entrance exam scores and high school grades. S\&S (2003a) discusses possible reasons that family income can play such an important role even when direct costs are zero.

\footnotetext{
${ }^{15}$ It is possible that roommates with high test scores could serve as good peers through the role model avenue even if they are not studying more than other students. These students do receive higher grades in college and it is possible that they could transfer a view that good grade performance is important even if they are not studying more. However, evidence about grade performance is not as easily observable to roommates as time-use. In addition, it takes a substantial part of the semester before a significant amount of evidence about grade performance becomes available to students.
} 
Given additional evidence in S\&S (2003c) that credit constraints are not particularly important for students at this school, some of the strongest possibilities are that students from low income families possess inferior study skills or lower propensities to study when they enter college, possess weaker beliefs about the importance of educational attainment, or do not receive the same amount of support and encouragement from their families if academic or social difficulties are encountered during college. If these type of explanations are relevant, then family income may play an important role in determining whether a person is a good role model. Unfortunately, it does not make sense to try to provide evidence about this matter using our time-use information from the 2000-2001 period because, while the drop-out rate of students (who can be thought of as a group of low income students) at Berea remained high during this period, the strong relationship between family income and grades (and retention) that was observed within the students at Berea during the 1991-1996 period is not observed during the 2000-2001 year. Nonetheless, given the theory/intuition discussed in Section IV and the findings of S\&S (2003a, 2003c) it seems sensible to take advantage of variation in family income when looking for evidence of peer effects at Berea.

Institutional details imply that the roommate assignment process is random. Nonetheless, given the importance of the randomness in this application, it is worthwhile to provide as much indirect evidence as possible that the process is indeed random. To do this we examined several specifications relating a student's observable characteristics to those of his/her roommate. In one specification, we regressed (separately for males and females) a student's ACT score on the ACT score of his/her roommate (RACT) and a series of year dummy variables. ${ }^{16}$ The t-statistics associated with a test of the null hypothesis that the effect of RACT is zero are .023 and 1.073 for females and males respectively. In a second specification, we regressed (separately for males and females) a student's high school grade point average (HSGPA) on the high school grade point average of his/her roommate (RHSGPA) and a series of year dummy variables. The t-statistics associated with a test of the null hypothesis that the effect of RHSGPA is zero are .702 and 1.188 for females and males

\footnotetext{
${ }^{16}$ Year dummies are needed to allow for the possibility that average test scores may vary somewhat by year.
} 
respectively. In a third specification, we regressed (separately for males and females) a student's family income (INCOME) on the family income of his/her roommate (RINCOME) and a series of year dummy variables. The t-statistics associated with a test of the null hypothesis that the effect of RINCOME is zero are .667 and 1.162 for females and males respectively. Thus, this indirect empirical evidence supports our belief, based on our knowledge of institutional details at Berea, that the roommate assignment process was random during this period.

The random assignment of roommates allows our methods for examining the influence of peer effects to be straightforward. For the purpose of examining grade outcomes, we begin by examining the results from the following three separate OLS regressions related to the first semester grade performance $\mathrm{G}_{\mathrm{i}}$.

(2a) $\mathrm{G}_{\mathrm{i}}=$ Constant $+\alpha_{\mathrm{ACT}} \mathrm{ACT}_{\mathrm{i}}+\alpha_{\mathrm{RACT}} \mathrm{RACT}_{\mathrm{i}}+v_{\mathrm{i}}$

(2b) $\mathrm{G}_{\mathrm{i}}=$ Constant $+\alpha_{\mathrm{HSGPA}} \mathrm{HSGPA}_{\mathrm{i}}+\alpha_{\mathrm{RHSGPA}} \mathrm{RHSGPA}_{\mathrm{i}}+v_{\mathrm{i}}$

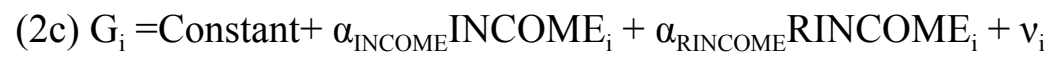

where each specification also includes a dummy variable for each of the years that a student could have entered Berea. ${ }^{17}$ The random assignment of roommates implies that RACT ${ }_{i}$, RHSGPA $_{\mathrm{i}}$, and RINCOME are uncorrelated with $v_{\mathrm{i}}$ which captures unobservable determinants of grade performance such as motivation, study skills, and study effort.

We make the specifications in (2a)-(2c) as simple as possible in the interest of making results easy to interpret. In particular, our initial approach of including one peer variable at a time allows the specifications to provide direct evidence about whether there actually exist people who are good peers at Berea without having to take into account relationships between multiple, strongly related peer variables. It is also worth noting that the random assignment of students implies that it would not be problematic to examine specifications that include roommate characteristics but do not include a student's own characteristics. However, we choose to include the student's own characteristics, i part, because knowing the estimated effect of the these variables is useful for understanding the importance of the estimated peer effects.

\footnotetext{
${ }^{17} 1996$ is chosen to be the omitted category.
} 
In all cases we estimate models separately by sex. The first three columns of Table 4a show the results of specifications (2a)-(2c) for females. The first column of Table 4 a reveals no evidence of a relationship between college grades and roommate ACT score; the estimated effect of RACT is .002 and a test of the null hypothesis that the effect of RACT is zero yields a t-statistic of approximately .401 . This finding is consistent with the discussion and empirical evidence in Section IV which suggested reasons why such a relationship might be unlikely to exist. Instead, Section IV suggested that, if peer effects are important in this context, it would be more likely to see evidence in the relationship between college grades and roommate high school grade point average. The second column of Table 4a provides such evidence; the estimated effect of RHSGPA for females is .176 and a test of the null hypothesis that the effect of RHSGPA is zero yields a tstatistic of 2.39. The third column of Table $4 \mathrm{a}$ reveals additional evidence of peer effects for females. The estimated grade effect of a $\$ 10,000$ increase in roommate family income is .050 and a test of the null hypothesis that the effect of RINCOME is zero yields a t-statistic of 2.09.

The results of Section IV indicated that a person's HSGPA has a larger effect on study-effort after conditioning on the person's ACT score. This suggests that RHSGPA may better differentiate between a roommate's value as a role model in a specification that also included RACT. This motivates the specifications in the fourth and fifth columns of Table 4a where RACT and ACT have been added to specifications ( $2 b)$ and $(2 c)$ respectively. In these specifications the point estimates associated with RHSGPA and RINCOME increase to .241 and .056 respectively, and tests of the null hypotheses that RHSGPA and RINCOME are unrelated to college grades yield t-statistics of 3.10 and 2.50 respectively in the two specifications. ${ }^{18}$

The five columns of Table $4 \mathrm{~b}$ show the results for males. Consistent with the discussion/evidence from

\footnotetext{
${ }^{18}$ We also reestimated column 2 and column 4 of Table 4a after pooling the data from the 1991-1996 period with the observations from the 2000-2001 period for which we observe that a student has a randomly assigned roommate. The estimated effect of RHSGPA remains very similar in column 2 and column 4, .176 and.239, respectively, and the t-statistics increase to 2.68 and 3.42, respectively. The estimated effect of RACT remains very close to zero in all cases. As discussed earlier, there is not a strong relationship between a student's own family income and his/her grade performance for the 2000-2001 period. As a result, it is not particularly informative to reestimate a pooled version of column 5 .
} 
Section IV and the finding for females, the first column of Table $4 \mathrm{~b}$ reveals no evidence of a relationship between college grades and roommate ACT score for males. However, Columns 2-5, which reveal no evidence of a relationship between a student's grades and the high school grade point average of his roommate and no evidence of a relationship between a student's grades and the family income of his roommate indicate differences in the importance of peer effects by sex. ${ }^{19}$ We also find evidence of such differences when we estimate specifications for retention that are analogous to the specifications in Tables $4 \mathrm{a}$ and $4 \mathrm{~b} .{ }^{20}$

Differences in the importance of peer effects by sex could arise for many reasons. In the educational context of this paper, one possibility is that females may be more accepting of roommates who are from different backgrounds, and, as a result, may spend more time with their assigned roommates than males. The BPS allows us to provide some empirical evidence that this may be the case. Specifically, when we repeat the analysis in Section III after separating the sample by sex, we find differences between males and females. For example, we find that .438 of females but only .297 of males report that their randomly assigned roommates are one of their four best friends. A test that the population proportions are the same for males and females is rejected at all traditional significance levels with the test yielding a t-statistic of 2.78 . We found that, on average, female students in the sample spent about $20 \%$ more time with their roommates. ${ }^{21}$ Our findings of differences by sex and the evidence about the possible reasons for this result are consistent with results outside of economics which have found, for example, that girls develop closeness and intimacy with friends more quickly than boys (Sharabany, Gershoni, and Hofman, 1981), have an easier time talking to

\footnotetext{
${ }^{19} \mathrm{We}$ also reestimated column 2 and column 4 of Table $4 \mathrm{~b}$ after pooling the data from the 1991-1996 period with the observations from the 2000-2001 period for which we observe that a student has a randomly assigned roommate. The estimated effect of RHSGPA in the two columns is .048 and .039 , respectively, and the tstatistics are .707 and .537 , respectively. The estimated effect of RACT remains very close to zero in all cases.

${ }^{20}$ For females we find strong evidence of a relationship between a roommate's family income and retention. Specifically, using a probit specification analogous to specification $(2 \mathrm{c})$ we find that the probability that a student returns for her second year increases by approximately .036 when her roommate's family income increases by $\$ 10,000$. A test that roommate family income plays no role in retention is rejected at traditional significance levels with a t-statistic of 2.63. However, consistent with our results from Table $4 \mathrm{~b}$, for males we found no evidence of a relationship between college retention and any of the peer variables.

${ }^{21}$ However, given small relatively sample sizes, it was not possible to reject the null hypothesis that the population mean time spent with roommates is the same for males and females.
} 
their same sex friends (Boyce, 2004, Ch.4), and have interactions that tend to be more personal in nature and involve more self-disclosure and emotional support (Maccoby, 1990, Wright, 1982). ${ }^{22}$

An important policy question is whether certain types of students can receive substantial peer benefits without other students incurring substantial costs. The discussion in this paper suggests that this could be the case. For example, it seems likely that a student with good study skills and/or strong beliefs about the importance of educational attainment would not suffer much from an arrangement in which she imparts these skills and beliefs on a roommate who came to school with poor study skill and/or weaker beliefs about the importance of educational attainment.

To get a sense of whether the net gains of combining students from diverse backgrounds might be positive we focus on women and begin by modifying the specification in the fourth column of Table $4 \mathrm{a}$. Specifically, the first column of Table 5 involves a specification in which we replace the HSGPA $\mathrm{H}_{\mathrm{i}}$ and RHSGPA $_{\mathrm{i}}$ variables (from the fourth column of Table 4a) with three dummy variables $\mathrm{HH}_{\mathrm{i}}, \mathrm{HL}_{\mathrm{i}}$, and $\mathrm{LH}_{\mathrm{i}}$ which indicate respectively 1) whether HSGPA $_{\mathrm{i}}$ and RHSGPA $_{\mathrm{i}}$ are both higher than the median high school grade point average in the sample; 2) whether $\mathrm{HSGPA}_{\mathrm{i}}$ is higher than the median and RHSGPA $\mathrm{i}_{\mathrm{i}}$ is lower than

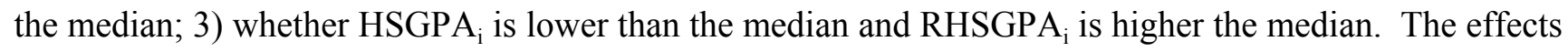
of these variables are relative to an omitted category in which both the student and her roommate have high school (H.S.) grade point averages that are lower than the median. Given this specification, the estimated effect of $\mathrm{LH}_{\mathrm{i}}, .242$, represents the estimated benefit to a student with low high school grades of being assigned a roommate with high high school grades rather than a roommate with low high school grades. The estimated difference between the effect of $\mathrm{HH}_{\mathrm{i}}$ and the effect of $\mathrm{HL}_{\mathrm{i}}, .074$, represents the estimated cost to a student with high high school grades of being assigned a roommate with low high school grades rather than a roommate with high high school grades. Therefore, an estimate of the net gain is $.242-.074=.168$. A test of the null hypothesis that the benefit from diversification is zero is rejected for all significance levels greater than .01,

\footnotetext{
${ }^{22}$ There is also other recent evidence in the economics of education literature that peer effects may differ by gender. For example, Hoxby (2000) finds evidence that students have better math performance when they are in classrooms that contain more females.
} 
and a test of the null hypothesis that the cost of diversification is zero can only be rejected at significance levels greater than .44. However, the net gain to diversification is imprecisely estimated, and a test of the null hypothesis that the net gain is zero is only rejected at significance levels greater than .21 .

Somewhat weaker findings are evident in the second column of Table 5 where we modified the specification in the last column of Table $4 \mathrm{a}$ in a similar fashion by constructing the HH, HL, LH indicators on the basis of the family income of a student and her roommate. The estimated benefit to a student from a low family income background of being assigned a roommate from a high family income background rather than a roommate from a low family income background is given by .150, and a test of the null hypothesis that the benefit is zero has a p-value of .06 . The estimated cost to a student from a high family income background of being assigned a roommate from a low family income background rather than a roommate from a high family income background is $.197-.138=.059$, and a test of the null hypothesis that the cost is zero has a pvalue of .48 . The net gain to diversification is $.150-.059=.091$, and a test of the null hypothesis that the net gain to diversification is zero has a p-value of .43 .

\section{Conclusion}

First year grade outcomes and drop-out decisions depend, in part, on the amount of effort a student puts into studying, the quality of his/her study time, and his/her beliefs about the importance of educational attainment. These factors may be influenced in the short run by the actions and beliefs of peers. This paper finds evidence which suggests that this avenue is important at Berea College and provides some direct evidence about why the importance of peers may vary by sex.

The findings and discussion in this paper are consistent with the recent work of Kremer and Levy (2003). They find that a student's grade performance during college is strongly related to his/her roommate's pre-college drinking behavior and conclude that "Overall, these findings are more consistent with models in which peers change preferences than models in which they change endowments." The findings and discussion are also consistent with recent work by Stinebrickner and Stinebrickner (2005). As part of an 
analysis of the causal effect of studying on academic performance, they find that students whose randomly assigned roommates bring video games to school have lower grades and provide evidence that this grade decline is caused by a reduction in study effort that accompanies game playing.

There are a couple of other things to note. First, the finding that a particular variable at Berea is related to whether a person is a good peer does not imply that a similar finding should be expected between the same variable and grade performance at a different school. There are several reasons the same relationship might not exist. Among these: 1) different types of students may be affected to a much different degree by peers than students at Berea and 2) the relationship between a particular observable characteristic, such as a person's high school grade point average or family income, and whether the person is a good role model (e.g., as suggested in this paper by the relationship between the characteristic and the person's time-use) may be quite different at a different school because these relationships will depend on a complex set of factors including the admissions process at a particular school. Nonetheless, given the difficulty of credibly identifying peer effects in education, much of the literature on peer effects in education has had the goal of trying to find compelling evidence that peer effects can matter. This paper provides evidence that peer effects can play a non-trivial role in higher education.

Second, the discussion in the paper suggests reasons that peer academic ability per se should probably not be expected to play an important role in the short-run academic outcomes studied in the college roommate literature, and the empirical work provides evidence in support of this notion. Thus, to the extent that the measures used in Sacerdote (2001) and Zimmerman (2003) primarily measure ability per se, this paper provides a possible explanation for the lack of evidence found in these previous papers. However, it is important to stress that the notion that peer ability per se does not matter in this particular educational context should not be taken as evidence that it does not matter more generally. For example, suppose that an elementary student is placed in a classroom with students who have the same study habits and beliefs about the importance of schooling but higher academic ability. Even in the short-run the student may benefit from these peers because the academic interactions between students in this context (e.g., students who spend the 
entire day in the same elementary school class) may be much greater than the academic interactions of college roommates. Further, even if the student's ability is to a large extent fixed in the short run, having high ability peers may make a difference over the many years that the students spends with his elementary classmates. 


\section{References}

Boyce, William: Young People in Canada: Their Health and Well-Being, Health Canada, 2004.

Foster, Ruth (2003): "Peerless Performers: The Absence of Robust Peer Effects at a Large, Heterogeneous University, working paper.

Hoxby, Caroline (2000): "Peer Effects in the Classroom: Learning from Race and Gender Variation."

Kremer and Levy (2003): "Peer Effects and Alcohol Use Among College Students," working paper.

Maccoby, E.E. (1990)," Gender and relationships: A developmental account," American Psychologist, 45:513-520.

Sacerdote, Bruce (2001): "Peer Effects with Random Assignment: Results for Dartmouth Roommates," Quarterly Journal of Economics, volume 116.

Sharabany, R., R. Gershoni, \& J.E. Hofman (1981): "Girlfriend, boyfriend: Age and sex differences in intimate friendship," Developmental Psychology, 17:800-808.

Stinebrickner, Todd R. and Ralph Stinebrickner (2003a): "Understanding Educational Outcomes of Students from Low Income Families: Evidence from a Liberal Arts College with a Full Tuition Subsidy Program," Journal of Human Resources, Summer, 591-617.

Stinebrickner, Todd R. and Ralph Stinebrickner (2003b): "Working During School and Academic Performance," Journal of Labor Economics, 21(2), April, 473-491.

Stinebrickner, Todd R. and Ralph Stinebrickner: (2003c): “Credit Constraints and College Attrition,” Working paper, The University of Western Ontario.

Stinebrickner, Todd R. and Ralph Stinebrickner (2004). “Time-Use and College Outcomes," Journal of Econometrics, 121(1-2), 243-269.

Stinebrickner, Todd R. and Ralph Stinebrickner (2005). "The Causal Effect of Studying on Academic Performance," Working paper, The University of Western Ontario.

Wright, P.H. (1982): “Men's friendships, women's friendship and the alleged inferiority of the latter," Sex Roles, 8:1-20.

Zimmerman, David (2003): "Peer Effects in Academic Outcomes: Evidence from a Natural Experiment," The Review of Economics and Statistics, 85(1), 9-23 
Table 1

DESCRIPTIVE STATISTICS: ADMINISTRATIVE SAMPLE USED IN SECTION V

\begin{tabular}{|c|c|c|c|c|c|}
\hline \multirow{2}{*}{ Observable Characteristics } & \multicolumn{2}{|c|}{$\begin{array}{l}\text { female } \mathrm{n}=676 \\
\text { mean standard deviation }\end{array}$} & \multicolumn{3}{|c|}{$\begin{array}{l}\text { male } \mathrm{n}=619 \\
\text { mean } \quad \text { standard deviation }\end{array}$} \\
\hline & & & & & \\
\hline Own ACT Score & 43.27 & 6.60 & 41.67 & 7.06 & \\
\hline Own family income/10000 & 2.02 & 1.28 & 2.27 & 1.37 & \\
\hline Roommate ACT Score & 43.24 & 6.64 & 41.61 & 6.98 & \\
\hline Roommate family income/10000 & 2.02 & 1.29 & 2.27 & 1.37 & \\
\hline Own high school GPA & 3.35 & $.45 \quad(n=474)$ & 3.07 & .51 & $(n=464)$ \\
\hline Roommate high school GPA & 3.34 & $.45 \quad(n=474)$ & 3.07 & .51 & $(n=464)$ \\
\hline \multicolumn{6}{|l|}{ Student Outcomes } \\
\hline First semester college grade point average & 2.62 & $.79 \quad(n=638)$ & 2.31 & .94 & $(\mathrm{n}=585)$ \\
\hline Student returned for second year & 0.72 & & 0.64 & & \\
\hline
\end{tabular}

Note: This table shows descriptive statistics for a sample of students that entered Berea College as freshmen between 1991 and 1996. The sample size is smaller for Own high school GPA and Roommate high school GPA because high school GPA is missing for approximately $25 \%$ of our sample. 
Table 2

DESCRIPTIVE STATISTICS: FRESHMAN STUDY AMOUNTS FROM TIME-USE SURVEYS

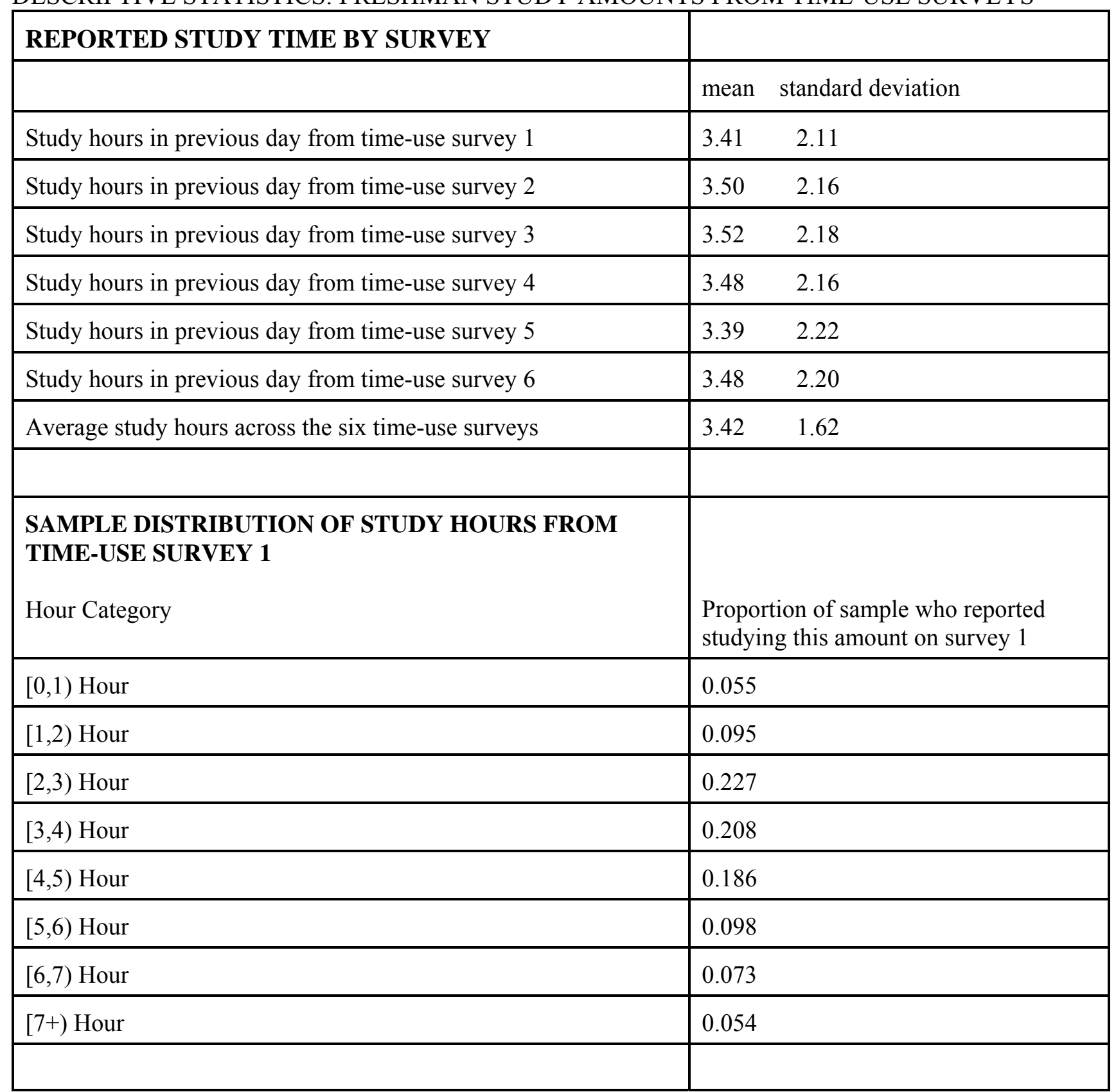

Note: This table shows descriptive statistics related to freshman study amounts for students who entered Berea College in 2000. Data come from time-use surveys administered as part of the Berea Panel Study. 
Table 3

THE RELATIONSHIP BETWEEN OBSERVABLE CHARACTERISTICS AND FRESHMAN STUDY HOURS

\begin{tabular}{|l|l|l|l|}
\hline & $\begin{array}{l}\text { EQUATION 1a } \\
\text { ACT } \\
\text { estimate (std. error) }\end{array}$ & $\begin{array}{l}\text { EQUATION 1b } \\
\text { HSGPA } \\
\text { estimate (std. error) }\end{array}$ & $\begin{array}{l}\text { EQUATION 1c } \\
\text { ACT \& HSGPA } \\
\text { estimate (std. error) }\end{array}$ \\
\hline OWN VARIABLES & & & \\
\hline Own ACT score & $-.038(.026)$ & & $-.095(.028)^{* *}$ \\
\hline Own high school GPA & & $.758(.212)^{* *}$ & $1.041(.223)^{* *}$ \\
\hline CONSTANTS & & & \\
\hline constant (time-use survey 1) & $4.346(.646)^{* *}$ & $.826(.769)$ & $2.096(.835)^{* *}$ \\
\hline constant (time-use survey 2) & $4.405(.638)^{* *}$ & $.886(.763)$ & $2.157(.826)^{* *}$ \\
\hline constant (time-use survey 3) & $4.377(.640)^{* *}$ & $.855(.764)$ & $2.123(.829)^{* *}$ \\
\hline constant (time-use survey 4) & $4.359(.641)^{* *}$ & $.847(.764)$ & $2.118(.828)^{* *}$ \\
\hline constant (time-use survey 5) & $4.331(.647)^{* *}$ & $.814(.755)$ & $2.084(.835)^{* *}$ \\
\hline constant (time-use survey 6) & $4.451(.644)^{* *}$ & $.933(.776)$ & $2.197(.837)^{* *}$ \\
\hline UNOBSERVABLES & & & \\
\hline standard deviation $\mu_{\mathrm{i}}$ & $1.349(.064)^{* *}$ & $1.317(.067)^{*}$ & $1.278(.068)^{* *}$ \\
\hline standard deviation $\varepsilon_{i, t}$ & $1.730(.027)^{* *}$ & $1.728(.027)^{*}$ & $1.727(.027)^{* *}$ \\
\hline & & & \\
\hline
\end{tabular}

* represents statistical significance at a .10 level.

** represents statistical significance at a .05 level.

Note: This table shows estimates of specfications (1a)-(1c). The specifications are estimated using multiple timeuse observations from the Berea Panel Study for 291 students who entered Berea in 2000. 
Table 4a

PEER EFFECTS ON FIRST SEMESTER GRADES FOR FEMALES

\begin{tabular}{|c|c|c|c|c|c|}
\hline & $\begin{array}{l}\text { EQUATION 2a } \\
\text { Peer Variable: } \\
\text { RACT } \\
(\mathrm{n}=638) \\
\text { estimate(std. error) }\end{array}$ & $\begin{array}{l}\text { EQUATION 2b } \\
\text { Peer Variable: } \\
\text { RHSGPA } \\
\mathrm{n}=445 \\
\text { estimate(std. error) }\end{array}$ & $\begin{array}{l}\text { EQUATION 2c } \\
\text { Peer Variable: } \\
\text { RINCOME } \\
\mathrm{n}=638 \\
\text { estimate(std. error) }\end{array}$ & $\begin{array}{l}\text { Peer Variables: } \\
\text { RHSGPA \& } \\
\text { RACT } \\
\mathrm{n}=445 \\
\text { estimate(std. error) }\end{array}$ & $\begin{array}{l}\text { Peer Variables: } \\
\text { RINCOME \& } \\
\text { RACT } \\
\text { n=638 } \\
\text { estimate(std. error) }\end{array}$ \\
\hline \multicolumn{6}{|l|}{ OWN VARIABLES } \\
\hline Own ACT score & $.045 \quad(.004)^{* *}$ & & & $.024 \quad(.005)^{* *}$ & $.044(.004)^{* *}$ \\
\hline Own high school GPA & & $.891(.073)^{* *}$ & & $.749 \quad(.077)^{* *}$ & \\
\hline $\begin{array}{l}\text { Own family } \\
\text { income } / 10000\end{array}$ & & & $.088 \quad(.024)^{* *}$ & & $.058 \quad(.022)^{* *}$ \\
\hline \multicolumn{6}{|l|}{ PEER VARIABLES } \\
\hline Roommate ACT score & $.002 \quad(.004)$ & & & $-.010 \quad(.005)$ & $.0008(.004)$ \\
\hline $\begin{array}{l}\text { Roommate high school } \\
\text { GPA }\end{array}$ & & $.176 \quad(.073)^{* *}$ & & $.241 \quad(.077)^{* *}$ & \\
\hline $\begin{array}{l}\text { Roommate family } \\
\text { income } / 10000\end{array}$ & & & $.050 \quad(.024)^{* *}$ & & $.056 \quad(.022)^{* *}$ \\
\hline \multicolumn{6}{|l|}{ CONSTANTS } \\
\hline constant & $.581 \quad(.268)^{* *}$ & $-1.074(.356)^{*}$ & $2.294(.096)^{* *}$ & $-1.388 \quad(.389)^{* *}$ & $.446 \quad(.268)^{*}$ \\
\hline Year of entry is 1991 & $.031 \quad(.095)$ & $.305 \quad(.111)^{* *}$ & $.037 \quad(.105)$ & $.274 \quad(.105)^{* *}$ & $.101 \quad(.097)$ \\
\hline Year of entry is 1992 & $-.004 \quad(.100)$ & $.054 \quad(.108)$ & $.073 \quad(.106)$ & $.021 \quad(.110)$ & $-.038 \quad(.100)$ \\
\hline Year of entry is 1993 & $-.016 \quad(.095)$ & $.176 \quad(.125)$ & $.155 \quad(.101)$ & $.141 \quad(.107)$ & $.028 \quad(.095)$ \\
\hline Year of entry is 1994 & $-.057 \quad(.095)$ & $-.071 \quad(.114)$ & $.010 \quad(.107)$ & $-.080 \quad(.122)$ & $-.057 \quad(.094)$ \\
\hline \multirow[t]{2}{*}{ Year of entry is 1995} & $-.005 \quad(.100)$ & -.091 & $.005 \quad(.096)$ & $-.091 \quad(.111)$ & $-.028 \quad(.099)$ \\
\hline & $\mathrm{R}^{2}=.149$ & $\mathrm{R}^{2}=.276$ & $\mathrm{R}^{2}=.036$ & $\mathrm{R}^{2}=.280$ & $\mathrm{R}^{2}=.166$ \\
\hline
\end{tabular}

* represents statistical significance at a .10 level.

** represents statistical significance at a .05 level.

Note: The table shows regression estimates (standard errors). The dependent variable in each column is the first semester grade point average for females who entered Berea as freshmen between 1991 and 1996. The peer variables vary across columns and come from a person's first semester randomly assigned roommate. 
Table 4b

PEER EFFECTS ON FIRST SEMESTER GRADES FOR MALES

\begin{tabular}{|c|c|c|c|c|c|}
\hline & $\begin{array}{l}\text { EQUATION 2a } \\
\text { Peer Variable: } \\
\text { RACT } \\
\mathrm{n}=585 \\
\text { estimate(std error) }\end{array}$ & $\begin{array}{l}\text { EQUATION } 2 \mathrm{~b} \\
\text { Peer Variable: } \\
\text { RHSGPA } \\
\mathrm{n}=438 \\
\text { estimate(std. error) }\end{array}$ & $\begin{array}{l}\text { EQUATION 2c } \\
\text { Peer Variable: } \\
\text { RINCOME } \\
\mathrm{n}=585 \\
\text { estimate(std. error) }\end{array}$ & $\begin{array}{l}\text { Peer Variables: } \\
\text { RHSGPA \& } \\
\text { RACT } \\
\mathrm{n}=438 \\
\text { estimate(std. error) }\end{array}$ & $\begin{array}{l}\text { Peer Variables: } \\
\text { RINCOME \& } \\
\text { RACT } \\
\mathrm{n}=585 \\
\text { estimate(std. error) }\end{array}$ \\
\hline \multicolumn{6}{|l|}{ OWN VARIABLES } \\
\hline Own ACT score & $.042(.005)^{* *}$ & & & $.016(.006)^{* *}$ & $.041 \quad(.005)^{* *}$ \\
\hline Own high school GPA & & $.900 \quad(.076)^{* *}$ & & $.806(.081)^{* *}$ & \\
\hline $\begin{array}{l}\text { Own family } \\
\text { income/10000 }\end{array}$ & & & $.040 \quad(.028)$ & & $.018 \quad(.027)$ \\
\hline \multicolumn{6}{|l|}{ PEER VARIABLES } \\
\hline Roommate ACT score & $.0002 \quad(.005)$ & & & $.00 \quad(.006)$ & $.0008 \quad(.005)$ \\
\hline $\begin{array}{l}\text { Roommate high school } \\
\text { GPA }\end{array}$ & & $.054 \quad(.077)$ & & $.040 \quad(.083)$ & \\
\hline $\begin{array}{l}\text { Roommate family } \\
\text { income } / 10000\end{array}$ & & & $-.038 \quad(.028)$ & & $-.035 \quad(.027)$ \\
\hline \multicolumn{6}{|l|}{ CONSTANTS } \\
\hline constant & $.509(.310)^{*}$ & $-.707(.302)^{* *}$ & $2.242(.123)^{* *}$ & $-1.109(.379)^{* *}$ & $.539(.314)^{*}$ \\
\hline Year of entry is 1991 & $-.101 \quad(.128)$ & $.098 \quad(.126)$ & $-.076(.136)$ & $.052(.127)$ & $-.094 \quad(.130)$ \\
\hline Year of entry is 1992 & $.017(.126)$ & $.033 \quad(.129)$ & $-.008(.132)$ & $.023(.128)$ & $.020 \quad(.126)$ \\
\hline Year of entry is 1993 & $.138(.124)$ & $.164 \quad(.124)$ & $.243(.129)$ & $.118(.125)$ & $.137 \quad(.124)$ \\
\hline Year of entry is 1994 & $-.002(.124)$ & $.130 \quad(.134)$ & $.078(.130)$ & $.094(.134)$ & $.001 \quad(.124)$ \\
\hline \multirow[t]{2}{*}{ Year of entry is 1995} & $.120(.133)$ & $.064 \quad(.149)$ & $.147(.140)$ & $.033(.148)$ & $.125 \quad(.133)$ \\
\hline & $\mathrm{R}^{2}=.113$ & $\mathrm{R}^{2}=.271$ & $\mathrm{R}^{2}=.019$ & $\mathrm{R}^{2}=.285$ & $\mathrm{R}^{2}=.116$ \\
\hline
\end{tabular}

* represents statistical significance at a .10 level.

** represents statistical significance at a .05 level.

Note: The table shows regression estimates (standard errors). The dependent variable in each column is the first semester grade point average for males who entered Berea as freshmen between 1991 and 1996. The peer variables vary across columns and come from a person's first semester randomly assigned roommate. 
Table 5

PEER EFFECTS ON FIRST SEMESTER GRADES FOR MALES USING CATEGORIES

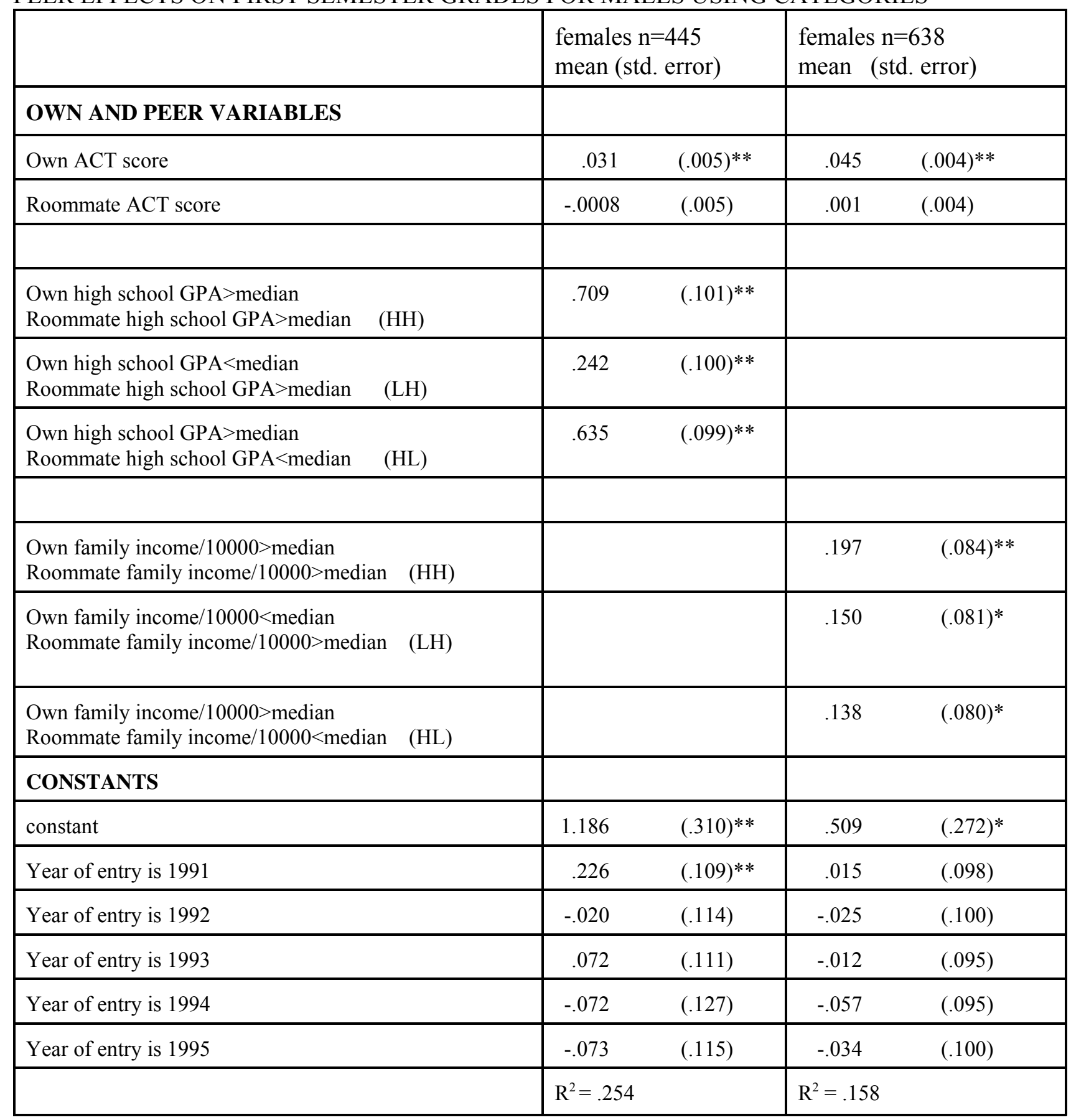

* represents statistical significance at a .10 level.

* represents statistical significance at a .05 level

Note: The table shows regression estimates and standard errors. The dependent variable in each column is the first semester grade point average for females who entered Berea as freshmen between 1991 and 1996. The omitted category in the first column is LL: Own high school GPA>median and Roommate high school GPA<median. The omitted category in the second column is LL: Own family income/10000>median and Roommate family income $/ 10000<$ median. The peer variables come from a person's first semester randomly assigned roommate 


\section{Appendix}

Question O. Please write down the first and last names of the four people (male or female) that have been your best friends at Berea College during this spring term (2002). That is, write down the names of the four people with whom you have been spending the most time during the spring term. Also please mention how many hours per week you spend with each person and how many hours you spend studying or talking about classes with each person.

Please include your boyfriend/girlfriend or husband/wife.

Also include your roommate if he/she is among your four best friends.

Place a check next to the name of your boyfriend/girlfriend or husband/wife.

Four best friends

Hours spent with this

Hours spent with this person

person in a typical week

studying /talking about

(don't include sleep hours) classes in a typical week

1.

2.

3.

4.

Place a check next to the name of your boyfriend/girlfriend or husband/wife.

Please fill out the following information for your current roommate and boyfriend/girlfriend spouse. Note that your current roommate and boyfriend/girlfriend/spouse (if any) should also appear above if they are among your four best friends.

Current Roommate's Name

Hours spent with this

Person in a typical week (don't include sleep hours)
Hours spent with this person studying/talking About classes in a typical week.

Boyfriend/Girlfriend/Spouse Name 
